\title{
Physicochemical and Microbiological Analyzes of Non-Alcoholic, Non- Carbonated Flavored Beverages Marketed in Plastic Bags in the City of Douala, Cameroon
}

\author{
Bamal Hans-Denis ${ }^{1}$, Mvogo Ottou Patrice Brice ${ }^{2}$, Ngoule Charles Christian ${ }^{1}$, Yinyang Jacques ${ }^{1}$, Etape Fabrice Edie ${ }^{1}$ \\ Kidik Pouka Cathérine ${ }^{1}$, Ngene Jean Pierre ${ }^{1}$, Kenmogne Simo Thiery ${ }^{1}$, Dibong Siegfried Didier ${ }^{1,2^{*}}$, Claus Jacob ${ }^{3}$, Etame \\ Loe Gisèle ${ }^{1}$ \begin{abstract}
${ }^{2}$ Department of Plant Biology, Faculty of Science, University of Douala, P.O. Box 24157 Douala, Cameroon
${ }^{3}$ Division of Bioorganic Chemistry, School of Pharmacy, Saarland University, Campus B2 1, Raum 1.14, D-66123, Saarbrücken, Germany
\end{abstract} \\ ${ }^{1}$ Department of Pharmaceutical Sciences, Faculty of Medicine and Pharmaceutical Sciences, University of Douala, P.O. Box 2701 Douala, Cameroon
}

DOI: $10.36348 /$ sipm.2020.v05i05.005 $\quad$ | Received: 02.05.2020 | Accepted: 09.05.2020 | Published: 12.05.2020

*Corresponding author: Dibong Siegfried Didier

\section{Abstract}

Flavored drinks are substances to be prepared or ready for consumption, including syrups and those containing caffeine. Their specific naming may be replaced by another, which is either usual or descriptive, such as "refreshing drink", "table drink" or "drink made from ..." that allows consumers to know the real nature of the beverage and to distinguish it from others. The quality of these dubious products is still poorly known although in terms of cost, they remain very accessible to the market. The objective of this experimental study was to contribute in improving awareness on the quality of these consumption items, by conducting physicochemical and microbiological analyzes of non-alcoholic and non-carbonated flavored beverages marketed in plastic bags in Douala, Cameroon. The physicochemical properties were evaluated by means of volumetric analysis, potentiometry, refractometry, titratable acidity and $\mathrm{SO}_{2}$ and vitamin $\mathrm{C}$ contents. Microbiological properties were assessed by performing a search for yeasts, molds and coliforms which sometimes act as antiseptic agents, such as ascorbic acid and citric acid. It would be necessary to review the production processes of these beverages as well as the enforcement of sanctions in salmonella and sulfate-reducing clostridium. Analyzes were performed on 50 samples in total. The results showed that $10 \%$ of the brands samples did not comply with the physicochemical quality standards. All brands samples met microbiological quality requirements, mainly due to a $\mathrm{pH}$ below 3 and the presence of preservatives with antiseptic properties. From the results obtained, it can be concluded that these drinks do not comply with the quality requirements defined by the standards for foodstuffs intended for human consumption. It would be of utmost importance to make improvements to the standards, the application of sanctions and to the production of better quality drinks, in order to ensure good food security for consumers.

Keywords: Flavored beverages, plastic bag, quality.

Copyright @ 2020: This is an open-access article distributed under the terms of the Creative Commons Attribution license which permits unrestricted use, distribution, and reproduction in any medium for non-commercial use (NonCommercial, or CC-BY-NC) provided the original author and sources are credited.

\section{INTRODUCTION}

Nowadays, in developing countries in general, and particularly in Cameroon, economic liberalism is perceived as a strategic option for real economic development and this context favors the development of new non-alcoholic flavored beverages, more adapted to low-income populations. Flavored beverages are those to be prepared or ready for consumption, including caffeinated syrups and drinks. Their specific name may be replaced by another that may be customary or descriptive, such as "lemonade", "refreshing beverage", "table beverage" or "drink made of..." that allows consumers to know the true nature of the commodity and to distinguish it from others [1].
In $1999,75 \%$ of non-alcoholic beverages in Cameroon were being consumed in the cities of Yaoundé and Douala [2]. Interviews and direct observations showed that in recent years, these products have been increasingly marketed in the streets of Douala, Cameroon, in the form of non-alcoholic, noncarbonated flavored drinks, in thermo-welded plastic bags, with manufacturing processes still poorly known.

However, food is a basic need for life, hence the need to develop adequate technologies and infrastructures to meet the demand for good quality food [2]. The aim of this experimental study was to help 
improve awareness on the quality of these consumption items. The specific objectives were to (1) evaluate the physicochemical analyzes and (2) determine microbiological properties of non-alcoholic, noncarbonated flavored beverages marketed in plastic bags in the city of Douala.

\section{METHODOLOGY \\ Type of the study}

This was an experimental study conducted between December 2017 and June 2018 in Douala. Samples collected on the field were sent to the Biology Laboratory of the Douala General Hospital for microbiological analyzes, and to the Quality Control Laboratory of Agro-food, Para-pharmaceutical and Cosmetic Products of the University Institute of Technology of Douala for physicochemical analyzes.

\section{Sampling}

Samples were taken in four markets, randomly selected in each district of the city, with the sole difference of the Madagascar market, which was replaced by a super market in the city (Santa Lucia) because of its high affluence. These are the Nkololoun, New Deido, Grand Hangar, Bepanda Double-Balle markets and Santa Lucia supermarket. The selection of samples was carried out following the description of non-alcoholic soft drinks of the Cameroonian standard NC 206: 2003-02 and the sampling plan was based on the European Commission's guidance document. In the absence of lot numbers on the vast majority of sample packages, five units were taken for each brand. In this report, the 10 brands names were given the following codes: A, B, C, D, E, F, K, SA, SB and LYA. A total of 50 samples were used for this study.

\section{Sample collection}

The samples were collected in a cooler with a cold accumulator.

\section{Physicochemical analyzes of beverages}

The volume was measured directly using a SIMAX class A glass graduated cylinder (orange graduation, capacity: $500 \mathrm{~mL}$, division: $5 \mathrm{~mL}$, Ø: 53.20 $\mathrm{mm}, \mathrm{H}: 380 \mathrm{~mm})$. The $\mathrm{pH}$ was determined by direct measurement using a previously calibrated $\mathrm{pH}$ meter (brand: HANNA HI 98107). Brix was determined using a previously calibrated Abbe refractometer (KERN optics). The titratable acidity was determined by titration as described elsewhere [3]. The results were obtained by multiplying the volume of the drop of burette (volume of $\mathrm{NaOH}$ ) by the coefficient of the citric acid which is equal to 0.64 , and expressed as citric acid content per unit volume.

Sulfur dioxide was measured using the Ripper method generally used for wines and musts, as described elsewhere [4].
For the determination of vitamin $\mathrm{C}$, the beverages were tested in the presence of dioxide solution, molar sulfuric acid and $1 \%$ soluble starch, using the inverse method to that described elsewhere [5].

\section{Microbiological analysis}

Three-class sampling plans were adopted for the yeasts and molds parameters and a two-class plan for coliforms (total and fecal), Salmonella and sulfatereducing Clostridium parameters.

\section{Search for, and enumeration of yeasts and molds}

For the yeasts and molds count, $0.1 \mathrm{~mL}$ aliquots of beverages and its decimal dilutions were seeded deep down in Sabouraud chloramphenicol agar. The colony count was performed after 5 days of incubation at $25^{\circ} \mathrm{C}$ according to standard NF ISO 7954.

\section{Search for total and fecal coliforms}

The search was performed by streak seeding on MacConkey agar [6].

\section{Search for Salmonella}

The search for Salmonella contains essential steps, namely: enrichment, streak and transplantation on Hektoen agar. The method was that specified by NFV 08-052.

\section{Search for sulfate-reducing Clostridium}

For anaerobiosis investigation of sulfatereducing bacteria, tryptone sulfite neomycin agar was used as a culture medium and the method was described by standard NFV 08-061.

\section{Data analysis}

Microsoft Word version 2010, Microsoft Excel version 2010 and SPSS version 2017 were used to record and process our data.

All data were recorded in an input mask and the results were presented taking into account mean \pm standard deviation terms. After verifying the normal distribution of the variables, the comparison of averages was performed by the two-factor non-repeat ANOVA test. The differences were considered significant at a threshold of $5 \%$.

\section{RESULTS}

\section{Physicochemical analyzes}

The physicochemical parameters data analyzed were compiled in Table 1.

\section{Volumetric analysis}

Of the analyzed beverages, one sample (BS) showed no report of the volume, and a significant difference was observed between the volumes measured and the volumes reported on the samples D, F, K, SA, SB; equivalent to $50 \%(25 / 50)$ of the samples. 


\section{PH measurement}

The expression of the $\mathrm{pH}$ measurement of the various samples was carried out taking into account the Cameroon standards for non-alcoholic refreshing beverages (description of beverages and $\mathrm{pH}$ values). None of the analyzed samples showed a $\mathrm{pH}$ beyond standard values.

\section{Brix determination}

The sugar levels were recorded to be in the range of 2 to $11^{\circ} \mathrm{B}$. The Brix values for the samples are as follows: $[\mathrm{E}, \mathrm{SB}]<\mathrm{F}<\mathrm{SA}<[\mathrm{LY}, \mathrm{K}]<[\mathrm{A}, \mathrm{B}, \mathrm{C}]<$ $\mathrm{D}$, with samples in square brackets having the same mean value (Table-1).

\section{Titratable acidity}

The titratable acidity calculation showed that brand B samples had the highest amounts of acid (2.11 $\mathrm{g} / \mathrm{L})$. The order of acidic content is as follows: $\mathrm{B}>\mathrm{D}>$ $\mathrm{K}>\mathrm{A}>\mathrm{LY}>\mathrm{C}>\mathrm{SA}>\mathrm{SB}>\mathrm{E}>\mathrm{F}$.

\section{Determination of free sulfur dioxide}

Results of the sulfur dioxide analysis were expressed in comparison to the value of sulfur dioxide from standard NC 206: 2003. The assayed samples showed very low concentrations of free sulfur dioxide compared to the standard, except for that of brand B samples $(10.39 \mathrm{mg} / \mathrm{L})$ which was slightly above the standard.

\section{Vitamin C dosage}

The vitamin $\mathrm{C}$ assay in the analyzed samples the presence of vitamin $\mathrm{C}$ in all samples but brand $\mathrm{C}$ samples, with small amounts in brands A, D, E, F, K, SA, SB and LY samples, while in brand B samples, the amount is much greater with a mass of $70.54 \mathrm{mg}$.

\section{Microbiological analyzes}

The results were interpreted in accordance with the formulation criteria for the interpretation of microbiological analyzes based on the European Commission's EC Regulation 2073/2005. They were rated as compliant or satisfactory, poor or acceptable and non-compliant or unacceptable or unsatisfactory (Table-2).

The results of the microbiological analyzes showed an absence of the desired germs in all fifty (50) analyzed samples, reflecting their conformities.

Table-1: Physicochemical parameters

\begin{tabular}{|c|c|c|c|c|c|c|c|}
\hline \multirow[t]{2}{*}{ Brands } & \multirow{2}{*}{$\begin{array}{l}\text { Number } \\
\text { of units }\end{array}$} & \multicolumn{6}{|c|}{ Physicochemical parameters } \\
\hline & & $\begin{array}{l}\text { Volume } \\
(\mathrm{mL})\end{array}$ & pH & $\begin{array}{l}{ }^{\circ} \text { Brix } \\
(\mathrm{g} / 100 \mathrm{~mL})\end{array}$ & $\operatorname{Acidity}(g / L)$ & $\begin{array}{l}{[\text { Free SO}} \\
(\mathrm{mg} / \mathrm{L})\end{array}$ & $\begin{array}{l}\text { Mass of vitamin } \\
\text { C/bag (mg) }\end{array}$ \\
\hline A & 5 & $196 \pm 5.3$ & $2.78 \pm 0.05$ & $9 \pm 0.5$ & $1.23 \pm 0.2$ & $4.27 \pm 7.35$ & $10.11 \pm 0.43$ \\
\hline $\mathrm{B}$ & 5 & $195.2 \pm 4.92$ & $2.92 \pm 0.55$ & $9 \pm 0.3$ & $1.47 \pm 0.25$ & $10.39 \pm 2.67$ & $70.54 \pm 0.20$ \\
\hline $\mathrm{C}$ & 5 & $99 \pm 5.19$ & $2.64 \pm 0.07$ & $9 \pm 0.4$ & $0.93 \pm 0.09$ & $3.42 \pm 3.67$ & 0 \\
\hline $\mathrm{D}$ & 5 & $124.2 \pm 1.04$ & $2.14 \pm 0.33$ & $11 \pm 0.15$ & $1.36 \pm 0.16$ & $1.71 \pm 1.83$ & $2.62 \pm 0.11$ \\
\hline $\mathrm{E}$ & 5 & $125 \pm 0.88$ & $2.52 \pm 0.05$ & $2 \pm 0.02$ & $0.74 \pm 0.18$ & $2.7 \pm 2.67$ & $2.93 \pm 0.05$ \\
\hline $\mathrm{F}$ & 5 & $131.8 \pm 6.65$ & $2.52 \pm 0.08$ & $4 \pm 0.15$ & $0.49 \pm 0.03$ & $3.26 \pm 2.22$ & $4.02 \pm 0.025$ \\
\hline $\mathrm{K}$ & 5 & $246 \pm 3.28$ & $2.7 \pm 0$ & $8 \pm 0$ & $1.25 \pm 0.24$ & $2.84 \pm 3.06$ & $7.79 \pm 0.27$ \\
\hline SA & 5 & $142 \pm 11.44$ & $2.4 \pm 0.09$ & $6 \pm 0.05$ & $0.87 \pm 0.09$ & $2.85 \pm 3.24$ & $3.83 \pm 0.05$ \\
\hline SB & 5 & $130.6 \pm 4.69$ & $2.52 \pm 0.14$ & $2 \pm 0.17$ & $0,81 \pm 0,22$ & $3.13 \pm 0.61$ & $4.13 \pm 0.11$ \\
\hline LY & 5 & $109 \pm 11.94$ & $2.64 \pm 0.07$ & $8 \pm 0.05$ & $1.1 \pm 0.03$ & $2.28 \pm 0.61$ & $2.30 \pm 0.04$ \\
\hline Standard & & l & $\leq 3$ & $\begin{array}{l}\text { threshold }= \\
2.5[7]\end{array}$ & I & 10 & I \\
\hline
\end{tabular}

Legend: ${ }^{\circ}$ Brix: degree Brix; /: no defined standard.

Table-2: Microbiological analyzes

\begin{tabular}{|c|c|c|c|c|c|c|}
\hline \multirow{3}{*}{ Brands } & & \multicolumn{4}{|l|}{ Germs/brand } & \multirow{3}{*}{ Interpretation } \\
\hline & \multirow[t]{2}{*}{$\begin{array}{l}\text { Number } \\
\text { of units }\end{array}$} & $\begin{array}{l}\text { Yeasts and } \\
\text { Molds }\end{array}$ & Coliforms & Salmonella & $\begin{array}{l}\text { Sulfate-reducing } \\
\text { Clostridium }\end{array}$ & \\
\hline & & $\begin{array}{l}10^{3}-10^{4} \\
\text { CFU/mL }\end{array}$ & $\begin{array}{l}\text { Absence } / 25 \mathrm{~g} \text { or } \\
\mathrm{mL}\end{array}$ & $\begin{array}{l}\text { Absence } / 25 \mathrm{~g} \text { or } \\
\mathrm{mL}\end{array}$ & $\begin{array}{l}\text { Absence/25 g or } \\
\mathrm{mL}\end{array}$ & \\
\hline A & 5 & 0 & ND & ND & ND & Compliant \\
\hline B & 5 & 0 & ND & ND & ND & Compliant \\
\hline $\mathrm{C}$ & 5 & 0 & ND & ND & ND & Compliant \\
\hline $\mathrm{D}$ & 5 & 0 & $\mathrm{ND}$ & ND & $\mathrm{ND}$ & Compliant \\
\hline $\mathrm{E}$ & 5 & 0 & ND & ND & ND & Compliant \\
\hline $\mathrm{F}$ & 5 & 0 & $\mathrm{ND}$ & ND & ND & Compliant \\
\hline $\mathrm{K}$ & 5 & 0 & ND & ND & ND & Compliant \\
\hline SA & 5 & 0 & ND & ND & ND & Compliant \\
\hline SB & 5 & 0 & ND & ND & ND & Compliant \\
\hline LY & 5 & 0 & ND & ND & ND & Compliant \\
\hline
\end{tabular}

Legend:

CFU: colony forming unit; ND: Not Detected. 


\section{DISCUSSION}

\section{Physicochemical analyzes Volumetric}

A significant difference was observed between the volumes measured and the volumes indicated by half of the samples analyzed. It can be explained by a non-existent filling chain or a manufacturing defect of the labels. Similarly, this difference may affect the information provided by these beverages analysis in comparison to the data on the package. It is necessary to standardize volumes to facilitate quality control of those products.

\section{pH Measurement}

None of the analyzed samples showed a $\mathrm{pH}$ above the recommended standard. According to these criteria, these samples can be considered compliant.

\section{Brix determination by refractometry}

The sugar content of the drinks analyzed varies between $2^{\circ} \mathrm{B}$ and $11^{\circ} \mathrm{B}$. These can be divided into two broad categories:

- Beverages with a sugar content $\leq 2.5 \mathrm{~g} / 100$ $\mathrm{mL}$ (brands $\mathrm{E}$ and $\mathrm{SB}$ );

- Beverages with a sugar content of $>2.5 \mathrm{~g} / 100$ mL (brands D, A, B, C, K, LY, SA and F).

The value of $2.5 \mathrm{~g} / 100 \mathrm{~mL}$ was chosen because it is a regulatory threshold as defined in the Annex of the Corrigendum to Regulation (EC) No $1924 / 2006$ for access to the claim "Low in sugar" [7]. Most of the analyzed samples (80\%) would therefore be contributors to sugar intakes; hence the major interest of children in their regard. This interest may also be due to a greater use of sweeteners compared to simple sugars. A standard for sugar content and sweeteners must be developed for better control of the sugar content of this product line.

\section{Titratable Acidity}

The results of the determination of the titratable acidity has shown that the amount of acid was between 0.49 and $1.23 \mathrm{~g} / \mathrm{L}$. It was expressed in terms of the amount of citric acid added in the samples. These results could confirm $\mathrm{pH}$ measurements below 3, although some brands samples mentioned other acids in addition to citric acid on their labels (list of ingredients).

\section{Determination of free sulfur dioxide}

The results of the sulfur dioxide analysis were expressed in comparison with the value of sulfur dioxide (10 mg/L) from standard NC 206: 2003 [8]. They showed that only brand B samples had a concentration $(10.39 \mathrm{mg} / \mathrm{L})$ slightly above the standard of $10 \mathrm{mg} / \mathrm{L}$. This $10 \%$ non-compliance rate can be explained by a lack of control of the chemical composition of these beverages before conditioning.

\section{Dosage of vitamin C}

The determination of vitamin $\mathrm{C}$ in all brands samples revealed an absence in brand $\mathrm{C}$ samples, and traces of vitamin $\mathrm{C}$ in other brands samples except brand $\mathrm{B}$ that had a much more important amount with a mass $70.54 \mathrm{mg}$. The purpose of vitamin $\mathrm{C}$ dosing in these beverages is to verify the vitamin $\mathrm{C}$-enriched nutritional claim on the labels of certain samples analyzed. Only brands A and B samples could justify the claim on their labels, unlike the rest of the brands samples having only traces of this vitamin. This difference demonstrates the urgent need to develop standards for the use of health claims and the allowable daily intake of vitamin $\mathrm{C}$ in this type of drink.

Among the physicochemical parameters sought, only two ( $\mathrm{pH}$ and $\mathrm{SO}_{2}$ levels) were derived from the Cameroonian standards. The absence of full regulation may encourage irresponsible behavior by players in this sector when producing batches, thereby placing consumers' health at risk.

It would therefore be of utmost importance to establish a specific technical sheet to facilitate the quality control of these products or to improve existing standards.

\section{Microbiological analyzes}

The total absence of germs in the analyzed samples is certainly due to the presence of unfavorable growing and living conditions such as a pH below 3 . Preservatives such as vitamin $\mathrm{C}$ and the citric acid present in the drinks sometimes play the role of antiseptic agents. This absence also indicates the probable presence of a heat treatment in the production system of these beverages and consequently a satisfactory or compliant microbiological quality. This quality is much higher than that obtained by Chenouf et al., [9], who showed a rate of non-compliance estimated at $13.33 \%$, the flavored beverages rate being $6.33 \%$, for a total of 30 samples analyzed and distributed in soft beverages (17), flat beverages (11) and juices (2). This rate was achieved because of yeasts $(13.33 \%$ of the brands samples), molds and coliforms $(3.33 \%$ of the brands samples).

\section{CONCLUSION}

The present experimental study was conducted on fifty (50) samples and contributed to a better knowledge of the physicochemical and microbiological qualities of non-alcoholic and non-carbonated flavored drinks marketed in plastic bags in the city of Douala, Cameroon. The results revealed a rate of noncompliance estimated at $10.0 \%$ due to a sulfur dioxide level higher than the maximum quantity required (10.39 $\mathrm{mg} / \mathrm{L})$. Each producer of these drinks has free hands on the dosage of sugar or vitamin C. On a microbiological aspect, the compliance of these beverages is due to the presence of unfavorable living conditions for the growth of desirable germs, with a very low $\mathrm{pH}$ and the 
presence of preservatives with antiseptic properties such as ascorbic acid and citric acid. Improvements to Cameroon's standards for pre-packaged foods and the enforcement of sanctions in production of beverages would be essential to ensure better food security for consumers.

\section{ACKNOWLEDGMENTS}

We thank DAAD for the fruitful scientific cooperation between the University of the Saarlandes (Germany) and the University of Douala (Cameroon).

\section{REFERENCES}

1. Département fédéral de l'intérieur. (2016). Ordonnance du DFI sur les boissons. Confédération, 16, 94.

2. Monkam, N. (1999). Le marché des boissons de fruits au Cameroun. Yaoundé: AGRO-PME, 1997, 17.

3. Ezoua, P., \& Kouamé, D. (1999). Caractéristiques du jus de la pulpe fraîche du fruit de ronier ("Borassus aethiopum" Mart.). Cahiers Agricultures, 8(2), 126-128.

4. Bonder, C., \& Silvestre, R. (2005). Pratiquer les contrôles analytiques en oenologie. Educagri Editions.

5. Pournaghi-Azar, M. H., \& Ojani, R. (1997). A selective catalytic voltammetric determination of vitamin $\mathrm{C}$ in pharmaceutical preparations and complex matrices of fresh fruit juices. Talanta, 44(2), 297-303.

6. Soleil, H. S., Minzangi, K., \& Mireille, K. K. (2014). Evaluation chimique et microbiologique des boissons locales nouvellement introduites et produites par la population du Sud-Kivu: cas des groupements de KATANA et BUGORHE [Chemical and microbiological evaluation of local beer introduced newly and produced by the people of the South-Kivu: case of Katana and Bugorhe territories]. International Journal of Innovation and Applied Studies, 8(2), 736.

7. Boeckel, T. P. V., Hounhouigan, J. D., \& Nout, R. (2003). Les aliments: transformation, conservation et qualité. CTA.

8. Agence des Normes et de la Qualité (ANOR). (2003). Norme camerounaise NC 206: 2003-02, des boissons rafraîchissantes sans alcool : Yaoundé : Agence des normes et de la qualité, p. 6.

9. Chenouf, A., Khirani, A., Yabrir, B., Hakem, A., Lahrech, B. M., Houali, K., \& Chenouf, N. (2014). Risque dû à la consommation des boissons rafraichissantes sans alcool édulcorées. Afrique Science. Revue Internationale des Sciences et Technologie, 10(4), 70-77. 